\title{
HISTORIC PRESERVATION IN THE CONTEXT OF ENVIRONMENTAL LAW: MUTUAL INTEREST IN AMENITY
}

\author{
MaLcolm F. BaLdWIN*
}

Growing numbers of people believe that the solution to our current environmental and social condition requires an increased public regard for something called "amenity" in our daily lives. Yet, many others who still consider "amenity" frivolous are not convinced that respect for cultural, historical and natural values can provide an answer to man's psychological and biological needs. Fortunately, the developing body of environmental law provides significant help to the advocate of "amenity." Because it is based on cultural as well as ecological perspectives, the emerging body of environmental law and the popular movement behind it offers citizen groups new legal and political means to bring about broad public protection of "amenity."

\section{I}

\section{The Environmental Defense of Amenity}

"Amenity," as recently defined by one author,

is not a single quality, it is a whole catalogue of values. It includes the beauty that an artist sees and an architect designs for; it is the pleasant and familiar scene that history has evolved; in certain circumstances it is even utility-the right thing in the right place-shelter, warmth, light, clean air, domestic service . . . and comfort stations. ${ }^{1}$

In short, amenity is often the reason why the secular life is worth living. Without it we enjoy neither individual nor community fulfillment. But historically our laws and institutions have tended to neglect the protection of this birthright. Amenity has not been so serious a matter as the pursuit of traditional forms of economic development. Those who usually shaped this policy had enough amenity. Today, however, the opportunity to neglect this aspect of life has disappeared. Environmental degradation has become a cause and a new social movement is the result. As Professor Joseph Sax describes it,

The plunder of our natural heritage at last brings home to us our equality-we must all breathe the same foul vapors. The well-to-do are not accustomed to being so dealt with; their frustration is now a seed that will bloom in many gardens. ${ }^{2}$

The development of a body of environmental law is indeed a response to ubiquitous degradation. While wilderness areas and parks have traditionally been afforded

\footnotetext{
-Senior Legal Associate, The Conservation Foundation, Washington, D.C.

${ }^{1}$ W. Johnson, Public Parks on Protite Land in England and Wales, at xi (I971) (quoting from Sir William Holford).

${ }^{2}$ J. SaX, Defending the Environment, A Strategy for Citizen Action 245 (1970).
} 
a modicum of legal protection, the environmental movement has been caught up during the last decade in the urgent need to protect much more of our air, water, and land from the grossest forms of abuse. Through legislation and litigation, lawyers have sought to highlight the social costs of pollution that have since World War II seemed to go unchecked, often basing these cases on possible long-term harm to human health. Most recently, environmental lawyers have been increasingly concerned about the impact of technology on man's surroundings-whether from highways, dams, or supersonic transports. But whatever the target, environmental lawyers generally act first of all to protect those basic human needs for amenity that the law has tended to neglect in the past.

This concern with human values is the touchstone of our environmental movement. We find that it must be reinforced with knowledge of ecosystems, resource limits, technology, and other matters often divorced from the humanities. For example, because we prefer clean air, genetic certainty and diversity in life, we must rely on what ecologists and other scientists tell us about the threats to these values from sulphur dioxide, radiation, or DDT. Because of our past and present experience, we must know what new technologies might cope successfully with continued energy doublings each decade.

But if we are prone to believe that there is a technological fix, that we have sufficient resources and scientific know-how to prevent our worrying about resource limits for generations to come, we must still take care to listen to others whose expertise is available to us. Social scientists suggest that we cannot collectively change habits as quickly as environmental efficiency might require. Concrete evidence from social scientists is badly needed. Conservationists may welcome this detailed kind of evidence, but their basic motivation may be of a much simpler order; they also share the simple wish of most of us to preserve the surroundings to which we are accustomed.

This fundamental human desire to control change may reflect the indelible influence of history on our individual perspectives. It has been said that

$[N]$ o matter how hard man tries it is impossible for him to divest himself of his own culture, for it has penetrated to the roots of his nervous system and determines how he perceives the world. ${ }^{3}$

We may sense the truth of this observation in several ways as the nation becomes more urban. For example, blacks brought up in the rural South or whites from Appalachia may undergo severe psychological stress when they change environments, moving from a simple, rural way of life to live in the crowded cities of the North. For many seeking to understand themselves and their new high-rise world, past experience is no help at all. They may tolerate a culturally unrelatable scene but will always find it difficult to adjust happily to it. The result may be individual neurosis and various forms of social alienation.

\footnotetext{
E. Harl, The Hidden DIMension 777 (Ig66).
} 
Being attuned to what are essentially human values, it is no surprise that conservationists generally are eager to know more about man's social, biological, or psychological constraints. Lacking much scientific information, however, their intuitive reaction is to resist the suggestion that a more automated, better organized world is necessary in order to preserve the simple values of clean air, water, and open space.

The essential point, of course, is that much of the present popular environmental concern is based not only on environmental values, but also on the conservationist's preference for the preservation of individual cultural and historic links. This value system puts a high premium on his need to maintain and develop a sense of pride in belonging to a larger community and on the need to live in an aesthetically pleasing man-made and natural world. Unfortunately, quite a different world confronts him, a world that is in his view culturally sterile and environmentally blighted. For example, take any shopping center. As described by Russell Baker,

There is only one shopping center in existence....

It moves around the continent at the speed of light. You find it at Wheaton, Md., and then-get on an airplane and fy like a bullet to escape the horror of itthere it is waiting for you at Irving, Tex., or Falmouth, Mass.

Or maybe it isn't moving around the country at all. Maybe it truly is everywhere. Maybe America really is a shopping center. ... Asphalt, stolidly menacing shelves of homogeneity marching off to a cement horizon; hot dogs and selfservice, mass-produced people and neon, a market with no smells. ${ }^{4}$

Technological ingenuity has enabled us to mass produce this item whose construction has little to do with the unique concepts of space and design of the New England, or southern, or southwestern culture. Our common law legal system of real property, which tends to put a premium on commercial trade and profit, has provided few practical restraints. We might wonder what Lord Mansfield would say if he saw the Anglo-Saxon world now.

\section{II}

\section{Public Poutcy in Defense of Amenity}

The spectre of the shopping center may come to haunt us even more as technology is mobilized to accommodate the more obvious environmental stress of economic and population expansion. Yet, it seems evident that just as bomb shelters may protect life, they cannot provide a good one. For the same reasons, simply "stopping pollution" does not begin to protect basic human values. It can hardly give us a reason for living, a sense of permanence, or a hope for individual and and social fulfillment. For those things, we must rely on the promotion of amenity that can come from a strong, and to some extent novel, public policy based on the following propositions:

"Baker, Vanishing America, N.Y. Times, Mar. 30, I971, at 35, col. I. 
First, amenity is a basic human need that must be freely available for the enjoyment of everyone in our society without regard to economic or racial status.

Second, to the extent that our present concept of amenity is not able to adjust quickly to economic and population change, the costs of any resulting loss of amenity should be fully and quickly pinpointed by public decision makers.

Third, public policy on such matters as land use, resource allocation, corporate responsibility, and legal procedure should be directed in ways that put the burden of economic cost on all those who would destroy amenity.

Utopian? Perhaps. But even skeptics might agree that a new public dedication to the pursuit of amenity is an option that increasing numbers of people already take seriously. Present legislation, particularly the National Environmental Policy Act of 1969 , is an implicit recognition by government of this new public attitude toward the protection of amenity. ${ }^{5}$ We now have both the constituency and the opportunity for effective argument before courts, administrative agencies, and legislatures that a new set of public policies with respect to amenity is required. Those policies must respect the principle that amenity is a public right, that the loss of amenity is the loss of an essential human right, and that the cost of amenity must be borne by those responsible for its loss.

\section{A. Amenity for Everyone}

A major pitfall is that amenity cannot be equitably distributed. Equitable distribution of the opportunity to enjoy amenity and the means of minimizing conflict and distributing amenity costs are rarely a matter of top priority to environmental interests. Efforts to preserve a wilderness might in some cases be characterized as elitist, but they are not so by design. More insidious are the attempts by many citizen groups to preserve community amenity through the use of exclusionary zoning practices-four acre zoning in the suburbs, for example-even though higher density, low-income cluster development might protect watersheds, woods, or open space just as well. Other community schemes, such as those calling for ecological land use planning or a moratorium on housing development-particularly in the face of low income housing needs-are similarly suspect. The pursuit of amenity by the white middle class should not proceed at the expense of those in the ghetto. Fortunately, the courts cannot be expected to permit this result. ${ }^{8}$

In particular, historic preservation groups have a special image of elitism to combat. Amenity as a preservation objective is too much related to history and architecture, to the preservation of a New England town, a southern plantation, or a city building of a particular period, appealing usually to a very narrow range of cultural and social interests. The Pittsburgh approach to preservation reverses this emphasis. There, historic interests focus on ways to preserve the character of neigh-

\footnotetext{
42 U.S.C. $\$ \S 4321-47$ (1970).

'Kennedy Park Home Ass'n v. Lackawanna, 3 I8 F. Supp. 669 (W.D.N.Y. 1970).
} 
borhoods and buildings based on their importance to the residents of that neighborhood. Robert Stipe has suggested that the value of this approach is that

the historically or architecturally important building or neighborhood comes to be viewed not merely as an interesting artifact of little relevance except for the well-educated tastes of the few . . . but as an important urban tesource of tremendous importance to the many. ${ }^{\text {? }}$

One might generalize from the experience of a very few such environmental and historic preservation groups to say that the vital ingredient to amenity seems to be a sense of community. In small towns and city neighborhoods, people do derive satisfaction from pleasant surroundings and the symbols of historical association. Support for this "sense of community" requires not only the preservation of a natural resource or a building, but the careful blending of the natural with the man-made world so as to relate the community to a total human need. While in theory environmental and historic preservation interests would probably agree that social justice and cultural diversity must both be observed, it may be more important that they energetically recognize the need to obtain a broad base of popular support. The environmental movement has already won some of this support; those who favor a strong public policy dedicated to the pursuit of amenity, especially in historic preservation, have a long way to go.

A tangible focus in the pursuit of amenity may be seen in plans for the Bicentennial. It can be argued that we need some re-thinking and reform of our federal transportation policy, and that such reform might be buttressed by the celebration of the 200th anniversary of American independence. The seeds for such a development have already been planted. ${ }^{8}$

Historic preservation and environmental interests have long recognized that interstate highways, freeways, and other highway projects can often disrupt the sense of community, cause urban sprawl, promote "strip cities," and cause other forms of human blight. Freeways frequently are the antithesis of environmental, historic, and cultural values. This point has not been lost in Washington, and controversy there over the construction of the Three Sisters Bridge has united conservation, preservation, and black community groups in a common effort to preserve the character of the Potomac gorge and the urban neighborhoods threatened by the connecting highways. ${ }^{9}$ Citizens in New Orleans, San Francisco, Memphis, San Antonio, and elsewhere have been similarly concerned about the effects of highways on the environmental and historic character and the community structure of these cities.

However, efforts to put highways in proper perspective must ensure that important social values are preserved without forcing transportation alternatives that

\footnotetext{
${ }^{7}$ Preservation News, Oct. I970, at 7, col. I.

${ }^{8}$ Friedlander, Progress Reports on U.S. Bicentennial, N.Y. Times, May 9, 197x, $\$$ ro ('Travel and Resorts), at 59, col. I.

'D.C. Federation of Civic Ass'ns v. Volpe, 308 F. Supp. 423 (D.D.C. r970).
} 
work a hardship on the disadvantaged. Highways cannot be shunted away from parks or historic districts simply to tear up a ghetto and cause more noise, air pollution, and dislocation problems there. Those who are sensitive to the problem of devising alternative solutions to transportation problems are acutely aware of the need for improved governmental planning. There are, in fact, attractive, technologically feasible alternatives to most highways that can protect amenity on a broad scale. Rather than merely fight highway encroachment on a city-by-city basis, environmental and historic preservation interests should be in the forefront of a major effort to develop viable transportation alternatives. One idea tying in with the nation's coming 200th anniversary has been suggested. Called Polis ' $76,{ }^{10}$ it suggests that the nation develop a massive rail transportation scheme to move people along the east coast in the most modern and comfortable way. Each city would be free to choose the manner in which it would utilize its rail links to develop tourist attractions and civic improvements, based on the historical assets and individual celebrations to be found in each city on the system. The emphasis would be on maximum appreciation of historical sites and the cultural events planned around them, facilitated and enhanced by a pleasing, environmentally protective, and permanent transportation system.

This broad and imaginative scheme, developed by students at Harvard and MIT, is far more responsive to our needs, our history, and our culture than any new national program to preserve individual historic buildings or to construct a single bicentennial exposition. We quickly tire of temporary world fairs. What we really need are massive public schemes to preserve and enhance environmental and social amenity and to capture the public imagination. Polis ' 76 could do so.

\section{B. Legal Support of Amenity}

When it comes to precisely articulating the value of amenity, environmental and historic interests are frequently at a loss. Environmental lawyers frequently discover that their clients may be most disturbed about the visual loss or the destruction of objects and space that had psychological importance. After oil leasing off Santa Barbara, for example, great public indignation in that community arose from the mere sight of the oil rigs in the channel. The aesthetic complaint was passed over with little trouble since the economics of the situation was a far more powerful persuader. Elsewhere around the nation's shoreline the reaction has been the same. While the best reason to protect shorelines, whether from refineries, power plants, marinas, or other development, may be simply that the existing natural beauty is pleasing to many people, the commercial argument seems always to be more realistic and compelling.

If we could quantify these other values, it might help. In Appalachia, strip mining for coal is irrevocably damaging to vegetation and water. We have the

\footnotetext{
${ }^{10}$ Shepherd, Polis '76, Loox, Jan. I2, I97x, at 43-44.
} 
methods to measure the impact of strip mining in economic terms. But its greatest abuse may be the visual rape of an ancestral home or an ordinary neighborhood, and we are far from being able to justify these costs against the benefits derived from coal.

How can lawyers deal with these kinds of injury to amenity? Social science research would help, of course-if it could produce evidence as useful to the cause of amenity as that on which the court in Brown v. Board of Education ${ }^{11}$ was able to rely to show that segregation was psychologically harmful to blacks. Unfortunately, little work is being done to assess the social or psychological costs of amenity loss, although we do have some useful studies of recreation or tourist value and the beginnings, at least, of attempts to quantify limited kinds of aesthetic values. ${ }^{12}$ However, we badly need interdisciplinary studies of our perception of amenity, its value to the promotion of art and science, and the effects of rapid environmental and social change on amenity in both individual and community life.

Related to the need for research in amenity is our recent interest in assessing technology as related to environmental quality. The Senate Public Works Committee has been considering a proposal to create a National Environmental Laboratory (NEL) with up to five regional branches. ${ }^{13}$ Under the bill, introduced by Senators Baker and Muskie, ${ }^{14}$ the NEL governing board could receive up to $\$ 5^{\circ}$ million per year. The work of the NEL would focus first on the collection and dissemination of information on the environment; and second, on the development of alternative solutions to arrive at optimum environmental and social results based on redefined problem analysis. The NEL would examine technological abatement of present pollution and assess technology for pollution in the future after having assessed the economic, social, and environmental (including aesthetic) costs. Subjects that might be covered include energy production and use, waste management and recycling, and the use of toxic substances.

Certainly we must have this kind of information, but it will hardly suffice since the NEL proposal, and others like it, can not pretend to help us set social goals. In fact, however, it supposes that greater knowledge, better managed, can permit us to protect the environment if we wish, while still growing in population and in GNP. Perhaps the NEL concept assumes more than it should about human intelligence. In that event, our fears must be that the NEL may never present us with a full array of realistic social options to achieve a high level of environmental quality. We know, for example, that while the technology already exists to control much

\footnotetext{
${ }^{11} 347$ U.S. ${ }_{483}$ (1954).

${ }^{21}$ L. Leopold, Qunantitative Comparison of Some Aesthetic Factors Amonc Rivers (Geological Survey Circular 620, 1969).

${ }^{13}$ See ad Hoc Nel Concept Comattee, Oax Rtdge Natronal Laboratory, The Case for Natronax. Environmental Laboratories, 9ist Cong., 2d Sess. (Report Prepared for the Use of the Senate Comm. on Public Works; Comm. Print 1970).

14. II3, 92d Cong., Ist Sess. (197r).
} 
of our environmental abuse, it is too rarely used to advantage. Even where we do choose to apply the best available technology, pollution can often be triggered by human error-for example, the Santa Barbara spill or the wreck of the Torrey Canyon. Human irrationality and weakness constantly intervene to foil our best laid technological plans, and the consequences magnify with time. Social science research, however, being pragmatic, can build on these factors and reckon the chances of legal, cultural, and other human constraints on our making the wise, increasingly complex decisions that technologists would ask. Only social scientists, however imprecise their methods, can help advise use of viable alternatives to what might become a complete surrender to the golden calf of economic growth. However, National Environmental Laboratories or similar federal technological assessment programs could, without a comparable federal commitment to research on the nature of man's psychological and biological needs, do us a serious disservice. Massive federal support for the social sciences, as well as for humanities, should be rigorously endorsed by both environmental and historic interests.

\section{Shifts in the Burden of Proof}

National priorities that favor war, national prestige, or expansion may partly result from the unwillingness of public leaders to translate their personal regard for amenity-for beaches or suburban open space, for example-into public decisions. Why this should be true is a mystery. It may be due partly to man's failure, or perhaps fear, to articulate in serious public debate-in elections, in the press-the importance of amenity to our way of life. In this public forum, lawyers with historic and environmental interests may be able to make substantial contributions to political change. Their professional efforts, however, might best be directed toward a reform of the law itself. Even without the evidence of social scientists, they can begin to assist in the development of legal doctrines designed to protect amenity against irrevocable damage by private or public action.

One hopeful avenue is the further development of the public trust theory already convincingly articulated by Professor Sax. ${ }^{15}$ Based on the ancient Roman doctrine that one must use his property so as not to injure the property of another (sic utere tuo ut alienum non laedas), he points out that courts have protected private property rights for generations and that our nuisance law has relied on this principle. Moreover, from Roman days through English common law to our own time, the law has protected shorelines and rivers from private encroachment because they were considered part of the public domain. ${ }^{16}$ These traditional restraints on private property and the existing protection of public rights lead Professor Sax to suggest that air, water, sea, and other natural resources should all be embraced under the protection of a public trust through which citizens can obtain equitable

\footnotetext{
${ }^{15}$ SAX, supra note 2.

${ }^{10}$ See Sax, The Public Trust Doctrine in Natural Resource Law: Effective Judicial Intervention, 68 Mich. L. REv. 47 I (I970).
} 
or declaratory relief against environmental encroachment. He further suggests that in recent environmental cases the courts have taken a subliminal approach to public trust by remanding certain issues back to the legislature for clarification or by declaring a moratorium on a given project to allow public agencies to reconsider it. This developing shift in the burden of proof is hopeful, but it has only begun. To speed up this change, state legislation to implement the public trust theory has already passed in Michigan, ${ }^{17}$ and it has been introduced in Congress by Senators Hart and McGovern. ${ }^{18}$ The Senate bill is opposed by the Administration, however. Greater public support for the public trust theory will depend on a strong push by lawyers and others, especially from historic and environmental forces.

One basis for the public trust theory is that the existence of the resources to be protected is due to no human effort. These are said to belong to us all and to require public protection against individual excess for purely private gain. The same may not be so true of the man-made scene-an historic building, for example. But in a larger sense, the values represented even in this area may become common property by a kind of cultural right of entry or prescription. If amenity in general is a public right, then the conditions on which it depends should, like air and water, be publicly protected-preferably by public agencies but by citizens in court if necessary.

Perhaps a step in this direction, consistent with the public trust theory, is the further development of a doctrine of aesthtic nuisance where there is no other ground on which to protect against encroachment. One writer justifies it quite simply:

A cause of action is needed which can be utilized by private citizens and public officials alike to examine on an individual basis those activities which threaten the scenic resources. Acceptance of an aesthetic nuisance action would allow such an examination to be made. It might not always succeed in preventing the destruction of the landscape, but it would at least subject unaesthetic activities to an inquiry which is now absent, thereby compelling consideration of both the reasonableness of such activities and alternatives which might lessen or prevent their deleterious impact upon the environment. Considering the present, general disregard for the beauty of the environment, this would be no small step..$^{10}$

The theory of private remedy for aesthetic abuse is hardly radical. We have, after all, thousands of years of cultural history behind us during which time we have developed aesthetic sensibilities. Judicial relief of not only visual but other intangible offenses can certainly define individual property rights in this field. We have, of course, judicial precedent for the protection of amenity that, in itself, is hardly visual. Courts that protect neighborhoods against the location of cemetaries and funeral homes have shown a remarkable sensitivity. One court, after reviewing

\footnotetext{
${ }^{17}$ Micr. CoMp. LAws ANN. \$\$ 691.r20I-.1207 (Supp. I97I).

${ }^{18}$ S. r032, $92 d$ Cong., Ist Sess. (I97I).

${ }^{19}$ Note, Aesthetic Nuisance: An Emerging Cause of Action, 45 N.Y.U.L. REv. 1075 (1970).
} 
other state court decisions, justified its injunction against a proposed funeral home by stating that

These decisions rest not upon a finding that an undertaking parlor is physically offensive but rather upon the premise that its continuous suggestion of death and dead bodies tends to destroy the comfort and repose sought in home ownership. ${ }^{20}$

If the courts can protect us against thoughts of death they can surely be used to make us aware of life. Over time, they can and doubtless will establish a judicial concept of public rights to amenity that, like our developing pollution constraints, might strongly limit private property. The courts can also prod legislatures and public agencies to protect these community rights through the public planning process. We can only hope that in this area the law will move as quickly as the world around it.

\footnotetext{
${ }^{30}$ Powell จ. Taylor, 222 Ark. 896,263 S.W.2d 906, 907 (I954).
} 